Syed I. Hussain, MD

Osama O. Zaidat, MD

Brian-Fred M.

Fitzsimmons, MD

Correspondence \& reprint requests to Dr. Fitzsimmons: bfitzsim@mcw.edu
Supplemental data at www.neurology.org

\section{The Penumbra system for mechanical thrombectomy in endovascular acute ischemic stroke therapy}

\section{ABSTRACT}

Background: Efficacy of IV systemic thrombolysis is limited in patients with severe acute ischemic stroke and large-vessel occlusion. Mechanical thrombectomy has been the mainstay therapy in large-vessel occlusion. This review focuses on the Penumbra aspiration device.

Method: Literature review.

Results: The Penumbra prospective studies were reviewed and results are presented. The pivotal single-arm prospective trial that led to its approval by the US Food and Drug Administration enrolled 125 patients within 8 hours of symptom onset and demonstrated an $82 \%$ recanalization rate, to Thrombolysis in Myocardial Ischemia (TIMI) scores of 2 and 3 . The risk of symptomatic intracranial hemorrhage was 10\%, and modified Rankin Scale (mRS) score of $\leq 2$ was $25 \%$. In the postmarketing registry, 157 vessels were treated, with $87 \%$ achieving TIMI 2 and 3 recanalization and $41 \%$ having an $m R S$ score of $\leq 2$.

Conclusion: The Penumbra aspiration system is an effective tool to safely revascularize largevessel occlusions in patients within 8 hours of onset of acute ischemic stroke who are either refractory to or excluded from IV thrombolytic therapy. Further prospective, randomized controlled trials will be needed to address whether this ability translates into neurologic improvement and better functional outcomes for our patients. Neurology ${ }^{\circledR}$ 2012;79 (Suppl 1):S135-S141

\section{GLOSSARY}

AIS = acute ischemic stroke; BA = basilar artery; FDA = US Food and Drug Administration; IA = intra-arterial; ICA = internal carotid artery; $\mathbf{I C H}=$ intracerebral hemorrhage; ID = inner diameter; IMS = Interventional Management of Stroke; $\mathbf{M C A}=$ middle cerebral artery; $\mathbf{M E R C I}=$ Mechanical Embolus Removal in Cerebral Ischemia; $\mathbf{m R S}=$ modified Rankin Scale; NIHSS = $\mathrm{NIH}$ Stroke Scale; PROACT $=$ Prolyse in Acute Cerebral Thromboembolism; PS = Penumbra aspiration system; rtPA = recombinant tissue plasminogen activator; $\mathbf{S A H}=$ subarachnoid hemorrhage; $\mathbf{s} \mathbf{C H}=$ symptomatic intracranial hemorrhage; TIMI = Thrombolysis in Myocardial Ischemia.

In the race against time to salvage brain tissue in acute ischemic stroke (AIS), conventional IV thrombolytic therapy can be either ineffective or difficult to administer within the 4.5-hour treatment window. Mortality and dependency rates continue to be greater than $50 \%{ }^{1-3}$ despite IV thrombolytic therapy and best medical management, especially in patients with large-vessel occlusions such as the internal carotid artery (ICA) terminus, the proximal middle cerebral artery (M1, MCA), and the basilar artery (BA). It is for these patients, in particular, that interventional treatments for AIS have been advocated, including the use of endovascular devices to promote arterial recanalization. One such device is the Penumbra aspiration system (PS) (Penumbra Inc., Alameda, CA), which works on the principle of aspirating thrombus from an occluded artery that has caused acute cerebral ischemia. This device was approved for use by the US Food and Drug Administration (FDA) in January 2008.

PENUMBRA DEVICE The PS is a novel device designed to revascularize primarily large-vessel thromboembolic occlusions in the intracranial circulation. It has 2 main components. First is a reperfusion microcatheter that is attached to a suction pump and designed specifically to navigate through the intracranial circulation and effectively aspirate thrombus. The second is the separator, which is essentially an operator-controlled microwire that

From the Department of Neurology (S.I.H.), Michigan State University, East Lansing; and Departments of Neurology, Neurosurgery, and Radiology (O.O.Z., B.-F.M.F.), Medical College of Wisconsin, Milwaukee.

Go to Neurology.org for full disclosures. Disclosures deemed relevant by the authors, if any, are provided at the end of this article. 

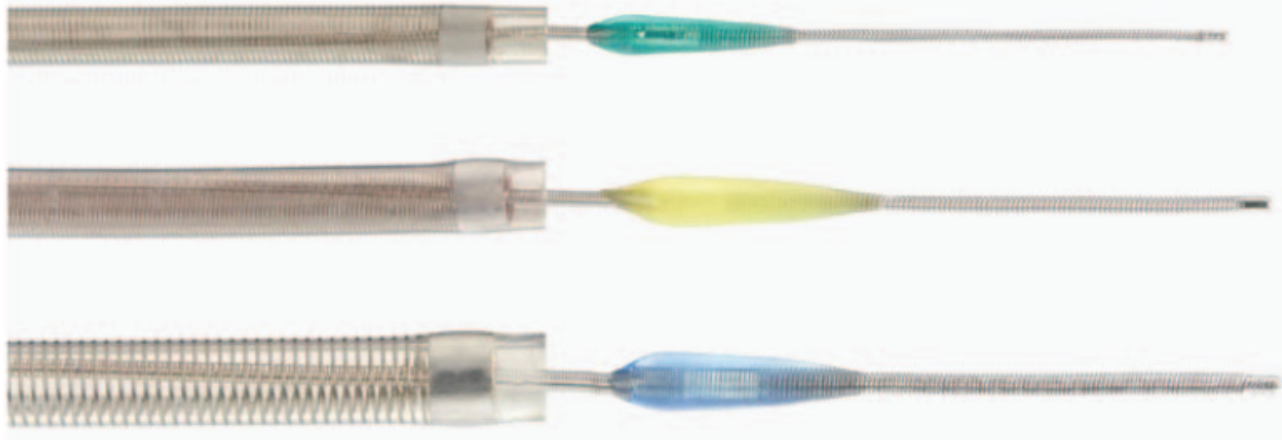

is inserted through the reperfusion catheter. It has a cone on its distal end that helps to clear ingested clot from the catheter tip and promote continuous aspiration. The reperfusion catheter is manufactured in 4 different sizes, with inner diameters (IDs) of 0.026, 0.032, 0.041 , and 0.054 inches, and is used with the corresponding size separator (figure 1). The reperfusion catheter/separator pair size chosen should be small enough to access the treatment site without causing occlusion or damage to the parent vessel wall but large enough to efficiently aspirate intraluminal thrombus. Typically, the 041 size is used for BA, ICA, vertebral artery, and M1 (MCA) occlusions with vessel diameters $>3 \mathrm{~mm}$.

For smaller vessels that are $2-3 \mathrm{~mm}$ in size, such as the M2 or P1 segments, the 032 pair is used, and for distal branches that are $<2 \mathrm{~mm}$ in diameter, the 026 pair is recommended. In the fall of 2009, the larger 054 ID reperfusion catheter and separator were developed and marketed to increase aspiration capability with large clots in proximal vessels, particularly the ICA and vertebral arteries.

The microcatheter/separator pair is attached via a rotating hemostatic valve to sterile tubing that connects to a proprietary aspiration pump, which generates 20 inches $\mathrm{Hg}$ of continuous negative suction. The minimum ID required to introduce the PS is 0.065 inches (6-Fr guide catheter) for the 026, 032, and 041 reperfusion catheters, and it is 0.080 inches (8-Fr guide catheter or 6-Fr long sheath) for the 054 catheter. However, navigating reperfusion catheters to the target occlusion through tortuous vessels can be challenging at times, particularly for the larger-size reperfusion catheters. Therefore, we find it helpful to support the PS with a 6-Fr long sheath $(90 \mathrm{~cm})$ in almost all circumstances. In addition, utilizing a tri- axial system to advance the 041 and 054 catheters can be critical. We prefer to advance the 041 reperfusion catheter over a $170-\mathrm{cm}$ Rapid Transit microcatheter (Codman, Raynham, MA) with a 0.014-inch Transend guidewire (Boston Scientific, Natick, MA). The 054 reperfusion catheter can be advanced over the Rapid Transit Microcatheter or the 032 reperfusion catheter with a 0.014 -inch to 0.018 -inch guidewire.

After positioning of the reperfusion catheter immediately proximal to the target occlusion, the guidewire is removed and replaced with the appropriate separator. The separator is advanced until its radiopaque marker is $4 \mathrm{~mm}$ distal to the marker on the reperfusion catheter. The pump is then turned on, and flow of blood is confirmed in the pump canister by visualization. The reperfusion catheter is then advanced slowly into the thrombus until flow slows or stops in the aspiration system. At this point, the reperfusion catheter has ingested clot, and the separator is then moved back and forth to clear the distal end of the reperfusion catheter and reestablish flow. In order to maximize flow within the reperfusion catheter, the separator is advanced again so that its radiopaque marker is distal to the distal end of the reperfusion catheter. This process is then repeated, each time slowly advancing the reperfusion catheter through the thrombus. If flow within the reperfusion catheter cannot be restored, it may be necessary to remove the catheter completely and manually flush the system with sterile normal saline outside the body before continuing. The product insert suggests aspirating for a maximum of 120 minutes, or $500 \mathrm{~mL}$ of blood loss.

Clinical trials. Phase 1 trial. A phase 1 prospective, multicenter, single-arm trial was performed at 6 in- 
ternational centers to assess the safety and performance of the PS in patients within 8 hours of symptom onset in AIS. ${ }^{4}$ The primary endpoint was the ability of the PS to revascularize the affected vessel to a Thrombolysis in Myocardial Infarction (TIMI) score of 2 or $3 .^{5}$

Secondary endpoints were the percentage of patients at 30 days with a modified Rankin Scale (mRS) score $<2$, a 4-point improvement on the NIH Stroke Scale (NIHSS) score, or mortality at 30 days. Enrollment was stopped at 23 patients because of higher than expected recanalization rates (100\%), as reported by the study group. Of note, however, patients were included in the study's final analysis only if the PS was successfully advanced to the site of occlusion. Of the 23 patients enrolled, only $20 \mathrm{pa}$ tients were included in the analysis, and 3 patients were excluded in whom the PS was unable to access the site of occlusion. If these 3 patients were included in the final analysis, the rate of access and recanalization for the PS in the phase 1 trial would be $87 \%$. The mean age of the study population was 60 years, and 8 patients $(40 \%)$ were women. The mean baseline $\mathrm{mRS}$ and NIHSS scores were $4.6 \pm 0.8$ and $21 \pm 8$, respectively. Eleven patients $(45 \%)$ had a baseline NIHSS score of $>20$, and another 3 had BA occlusions, for a total of 14 patients $(70 \%)$ with severe strokes associated with a high predicted mortality and morbidity. Fifty percent of the patients presented between 3 and 8 hours of symptom onset. Of the remaining $50 \%$, who presented within 3 hours, 6 subjects were refractory to recombinant tissue plasminogen activator ( $\mathrm{rtPA}$ ) and 4 were ineligible for IV thrombolytics. Among the 21 vessels treated by the PS, 7 (33\%) were ICA, 5 (24\%) were MCA, and 9 (43\%) were BA.

Of the 3 patients excluded, all had proximal lesions: 2 left M1 occlusions and 1 right supraclinoid ICA occlusion. None of these 3 patients had any immediate complications, and all were discharged to either a rehabilitation facility or nursing home; however, 1 patient died after 32 days from complications of heart failure. Of the 21 treated vessels, 19 had TIMI 0 flow and 2 had TIMI 1 flow at onset. After treatment with the PS, all vessels were successfully revascularized to TIMI 2 or 3 (table e- 1 on the $\mathrm{Neu}$ rology ${ }^{\circledR}$ Web site at www.neurology.org). Adjunctive therapy with intra-arterial (IA) rtPA was used in 9 patients, with a dose range of 10 to $45 \mathrm{mg}$ at the discretion of the neurointerventionalist if distal thrombus was noted. However, the final TIMI flow scores were recorded before any adjunctive treatments were administered and after the PS aspiration was considered complete by the operator. Forty-five percent of patients treated with PS (9/20) achieved at least a 4-point improvement on the NIHSS score or an mRS score of at least 2 at 30 days. Nine patients had an improvement of 4 or more points on the NIHSS score and 7 patients had an mRS score of at least 2. Patients with an NIHSS score $>20$ at baseline were less likely to have improvement at 30 days postprocedure. The overall mortality rate was $45 \%$, with 9 patients dying within the 30-day study period. None of these deaths were considered related to the device or clot extraction. Most deaths were related to either cerebral edema or hemorrhagic conversion of the previously infarcted area.

Two procedural adverse events in 2 separate patients were reported. One patient experienced a groin hematoma requiring blood transfusion but no surgical intervention.

The second event was a device-related subarachnoid hemorrhage (SAH) that did not lead to neurologic deterioration and did not require any further interventions. Intracranial hemorrhage (ICH) occurred in 8 patients, of which 2 were considered symptomatic (sICH), as defined by a deterioration in NIHSS score of $>4$ points. ${ }^{6}$ In all 8 patients, adjunctive thrombolytic therapy was involved (7 with IV and 1 with IA administration of rtPA). One of the $\mathrm{ICH}$ patients presented with SAH. This phase 1 trial set out to demonstrate that the PS could successfully revascularize large-vessel occlusions in AIS caused by thromboembolism. Unequivocally, the PS demonstrated a $100 \%$ recanalization rate. However, it also illustrated the potential difficulty of navigating the PS to the target lesion through tortuous anatomy (87\% success rate).

Phase 2 trial. The Penumbra Pivotal Stroke Trial ${ }^{7}$ was a single-arm, prospective multicenter trial that was conducted to assess the safety and effectiveness of the PS in 24 international centers; the trial report was published in the fall of 2009. The primary endpoints of this study were revascularization to TIMI $2 / 3$, as adjudicated by a core laboratory before the use of any adjuvant therapy, and device- or procedure-related adverse events. Secondary endpoints included the rate of sICH at 24 hours, 10-point improvement in NIHSS score at 7 days, mRS score $<2$ at 30 days or $<2$ at 90 days, and mortality at 30 and 90 days. The Merci clot retriever (Concentric Medical, Mountain View, CA) was used as the predicate device and historical control. ${ }^{8-11}$ These endpoints and historical controls were agreed upon with the FDA prior to the start of this study. Data from this trial were used to receive $501(\mathrm{k})$ clearance from the FDA for commercial use of the Penumbra aspiration system in the United States. Inclusion criteria were age 18 to 79 years with AIS, presenting within 8 hours of symptom onset, and with an NIHSS score $>8$. The pa- 


\begin{tabular}{|c|c|c|c|c|c|}
\hline \multirow{3}{*}{$\begin{array}{l}\text { Table } 1 \\
\text { Outcome }\end{array}$} & \multicolumn{5}{|c|}{$\begin{array}{l}\text { Penumbra Pivotal Trial: Patient outcomes and effects } \\
\text { of revascularization }\end{array}$} \\
\hline & & \multicolumn{3}{|c|}{ Percentage of patients with outcome } & \multirow[b]{2}{*}{ p Value } \\
\hline & & $\begin{array}{l}\text { Overall } \\
(n=125)\end{array}$ & $\begin{array}{l}\text { Open vessel } \\
(n=102)\end{array}$ & $\begin{array}{l}\text { Closed vessel } \\
(n=23)\end{array}$ & \\
\hline \multicolumn{2}{|c|}{ 10-point NIHSS improvement at $7 \mathrm{~d}$} & 25 & 30 & 0 & 0.0017 \\
\hline \multicolumn{2}{|c|}{$\mathrm{mRS} \leq 2$ at $30 \mathrm{~d}$} & 23 & 26 & 8 & 0.1003 \\
\hline \multicolumn{2}{|c|}{ Good clinical outcome ${ }^{a}$ at $30 \mathrm{~d}$} & 30 & 36 & 8 & 0.0120 \\
\hline \multicolumn{2}{|c|}{$\mathrm{mRS} \leq 2$ at $90 \mathrm{~d}$} & 25 & 29 & 9 & 0.0596 \\
\hline \multicolumn{2}{|c|}{ Death at $30 \mathrm{~d}$} & 26 & 25 & 35 & 0.3085 \\
\hline \multicolumn{2}{|c|}{ Death at $90 \mathrm{~d}$} & 33 & 29 & 48 & 0.1384 \\
\hline
\end{tabular}

Abbreviations: $\mathrm{mRS}=$ modified Rankin Scale score; NIHSS = NIH Stroke Scale score. a Good clinical outcome $=10$-point NIHSS improvement at 7 days or $\mathrm{mRS} \leq 2$.

tient must have been ineligible or refractory to IV rtPA therapy. Additional protocol requirements included baseline angiography findings of TIMI 0 or 1 flow in the target vessel. The exclusion criteria included NIHSS score $>30$ or coma, vessel tortuosity precluding endovascular access, CT evidence of significant mass effect with midline shift, large hypodensity region $>1 / 3$ of the MCA territory, any evidence of $\mathrm{ICH}$, and angiographic evidence of an arterial stenosis proximal to the occlusion that could prevent thrombus removal or preexisting arterial injury.

A total of 856 patients were screened in the 24 international centers, of which 125 patients were successfully enrolled, with a mean $( \pm S D)$ age of $63.5 \pm 13.5$. Nearly half of the patients were female (49\%). At baseline, the mean NIHSS score was $17.6 \pm 5.2$ and the mRS score was $4.5 \pm 0.8$. The arterial occlusions were predominantly in the anterior circulation: $70 \% \mathrm{MCA}$ and $18 \% \mathrm{ICA}$, with the vertebrobasilar circulation and other territories accounting for $9 \%$ and $3 \%$, respectively. Mean time to presentation was $1.9 \pm 1.6$ hours, and median time from onset to arterial puncture was $4.3 \pm 1.5$ hours.

The pre- and postprocedure distribution of TIMI scores is shown in table e-2. Patients were revascularized successfully $(81.6 \%)$ to TIMI $2 / 3$ with the use of the PS, and the median time to achieve this score was 45 minutes of aspiration. The success of revascularization was equal in both ICA and MCA occlusions. Baseline NIHSS score was not a predictor of successful revascularization but was significantly associated with functional outcome (see below).

There were 19 procedural events that occurred in 16 patients (12.8\%), of which 3 patients (2.4\%) had complications that were rated as serious by the Clinical Events Committee. Of these 3 patients, 1 had a severe reperfusion $\mathrm{ICH}$; the second had an $\mathrm{SAH}$ after angioplasty for a distal thrombus; and the third had an SAH from a snare and angioplasty used to treat a distal occlusion not accessible with the PS. The for- mer 2 complications were fatal, but the other patient recovered.

The ICH rate at 24 hours was $28 \%$ (35 patients), and $11.2 \%$ (14 of those patients) were symptomatic. Among all ICH cases, 4 were SAH and 2 were European Cooperative Acute Stroke Study (ECASS) 2-defined type 2 parenchymal hematoma. Among the 35 patients with ICH, 12 received thrombolytic therapy. Of the 14 patients with sICH, 6 had received either IV (4 patients) or IA (2 patients) thrombolytic therapy. It was concluded that concomitant use of thrombolytic therapy did not significantly affect the safety or ICH rate of the PS.

The clinical outcomes data are summarized in table 1 . An improved NIHSS score of $>10$ points at 7 days was achieved in $25 \%$, and an mRS score $<2$ at 30 days was achieved in $23 \%$. A good clinical outcome was defined as either a 10-point improvement in the NIHSS score at 7 days or an mRS score $<2$ at 30 days. This good clinical outcome occurred in $30 \%$ of patients. The mRS score did not show much improvement by 90 days and was still only $25 \%$. The overall 30 -day and 90 -day mortality rates were $26 \%$ and $33 \%$, respectively.

Additional analysis of the outcome measures was performed based upon the success or failure of revascularization. This analysis is also summarized in table 1. Successful revascularization was associated with improved NIHSS scores and good clinical outcome at 30 days, with statistical significance. There was a suggestion of improved mRS scores and decreased mortality with successful revascularization, but none of these endpoints reached statistical significance. Further analyses revealed that baseline NIHSS score $>20$, prior stroke, and large-vessel occlusion increased mortality, whereas an NIHSS score $<20$ was the only independent predictor of a good functional outcome.

The POST trial. This was a postmarketing study that looked at real life experience with the PS, following regulatory approval in the United States and Europe. A total of 157 patients were retrospectively enrolled in this multicenter registry, with mean baseline NIHSS score of $16 \pm 6$ within 8 hours of symptom onset. Similar to the Pivotal Trial, a high rate of recanalization to TIMI 2 and 3 was found (87\%). However, reported clinical outcome (available on 122 patients) was better in the POST trial, ${ }^{12}$ with $41 \%$ achieving an $\mathrm{mRS}$ score $\leq 2$ at 3 months, vs $25 \%$ in the Pivotal Trial. The rate of total ICH was $21 \%$, with $6.4 \%$ symptomatic. Mortality was $20 \%$.

Case example. A 74-year-old man (figure 2) with a history of atrial fibrillation developed left-sided weakness of sudden onset. He presented to the emer- 


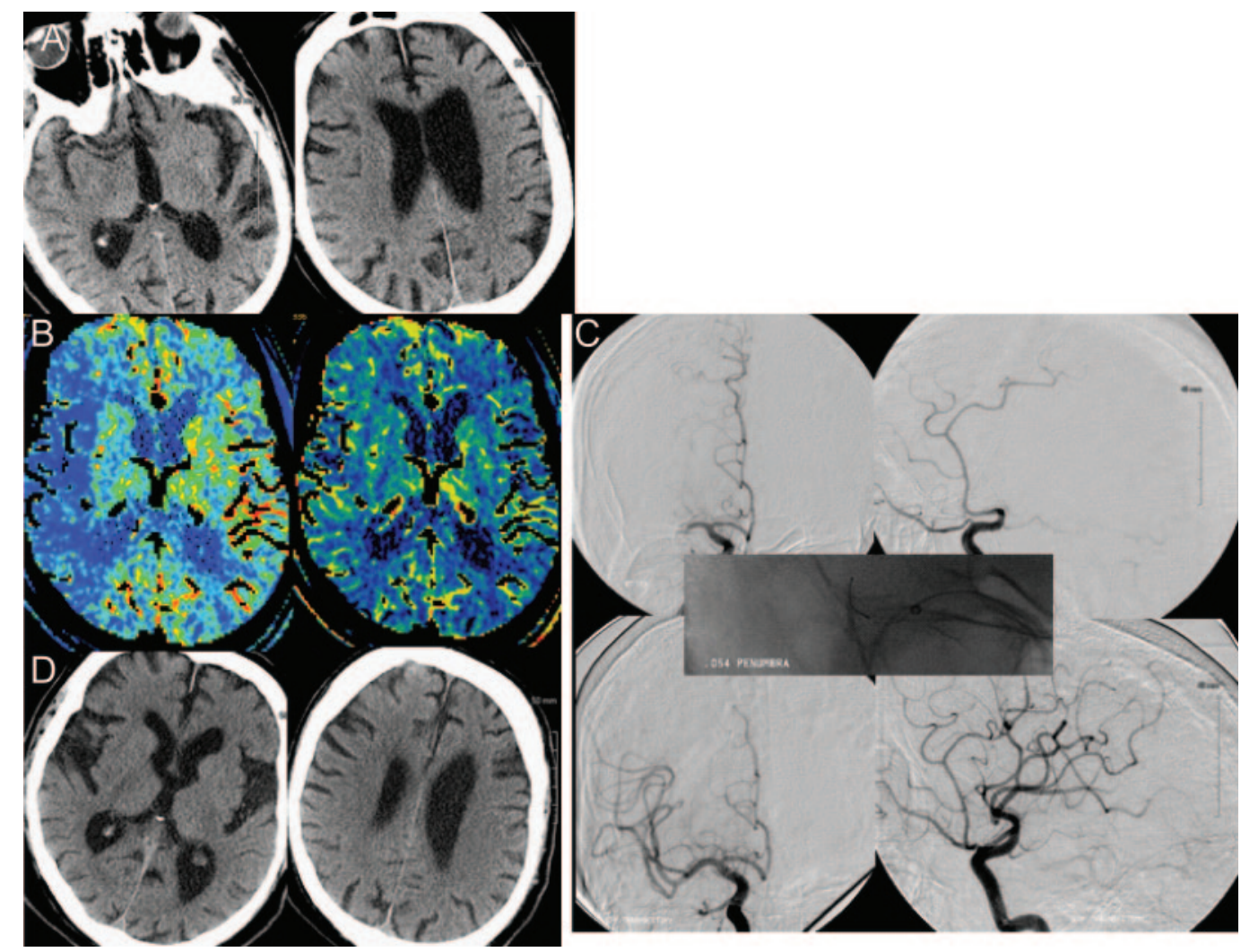

Baseline CT scan of the head shows right M1 complete occlusion with hyperdense right middle cerebral artery sign on the left upper corner (A); large mismatch was noted on CT perfusion. (B) Cerebral blood flow on the left and cerebral blood volume on the right. (C) Angiogram in anteroposterior and lateral views, showing the Thrombolysis In Myocardial Ischemia (TIMI) 0 occlusion, with TIMI 3 on the final image, after the use of Penumbra system 0.54 reperfusion catheter (right upper and lower rows). The final CT scan (D) showed no significant infarction.

gency department with left hemiplegia, facial weakness, and severe dysarthria (NIHSS score of 12) at 4.5 hours from symptom onset. Initial head CT showed a hyperdense right MCA sign. CT angiography of the head revealed a proximal right MCA occlusion with significant mismatch on CT perfusion. After 45 minutes of aspiration using the 054 PS, the initial occlusion improved from TIMI 0 to TIMI 3 with subsequent near-complete neurologic recovery within 24 hours. The patient was discharged home for independent living with an mRS score of 1 .

DISCUSSION The hyperacute treatment of patients with AIS currently focuses on vessel recanalization, which, if achieved promptly, could potentially reduce disability and mortality. ${ }^{13}$

Experience has revealed, however, that patients with large-vessel occlusions still have significant mortality and disability despite the use of IV thrombolytics. ${ }^{14,15}$ This is partly due to the low recanalization rates achieved with IV thrombolytics in the setting of large artery occlusions. Acute recanalization rates for
MCA and ICA occlusions with IV rtPA are reported to be less than $25 \%$ and $10 \%$, respectively. ${ }^{16}$

As a result, local administration of IA thrombolytic therapy was studied in the second PROlyse in Acute Cerebral Thromboembolism Trial (PROACT II), ${ }^{8}$ and the Interventional Management of Stroke 1 \& 2 Trials $^{17,18}$ (IMS I, IMS II). In PROACT II, the use of IA prourokinase achieved recanalization in $66 \%$ of treated MCA occlusions (20\% complete recanalization and $46 \%$ partial recanalization). IMS I and II reported TIMI $2 / 3$ recanalization rates of $56 \%$ and $60 \%$, respectively, with the combined use of IV and IA rtPA in addition to endovascular ultrasound therapy in IMS II.

Mechanical thrombectomy in AIS has been developed in an effort to increase the rates of recanalization for large-vessel occlusions while limiting the systemic and cerebral risks of thrombolytic therapy. The first mechanical device to be approved for cerebral thrombectomy in North America and Europe was the Merci retriever (Concentric Medical, Mountain View, CA) ${ }^{8-11}$ Published data for the Merci re- 
Figure $3 \quad$ Procedural results from interventional stroke trials

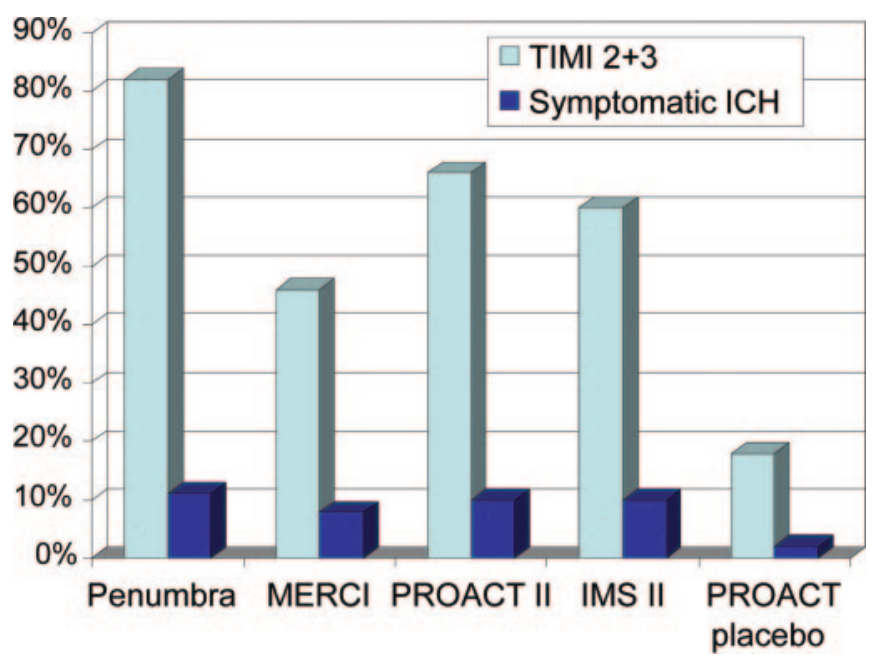

IMS = Interventional Management of Stroke; MERCI = Mechanical Embolus Removal in Cerebral Ischemia; PROACT = Prolyse in Acute Cerebral Thromboembolism; TIMI = thrombolysis in myocardial ischemia.

triever revealed successful recanalization (TIMI 2/3 flow) in $48 \%$ ( 141 subjects), with a $7.1 \%$ procedural adverse event rate and $7.8 \% \mathrm{sICH}$ rate. When the Merci retriever was combined with thrombolytic therapy (IV/IA rtPA) and next-generation Merci devices were used (Multi-MERCI), the recanalization rate increased to $69.5 \%$, with an sICH rate of $9.8 \%$. The Penumbra Pivotal Trial report described slightly

\section{Figure 4 Percentage of patients with modified Rankin scale score of 0-2 at} 90 days

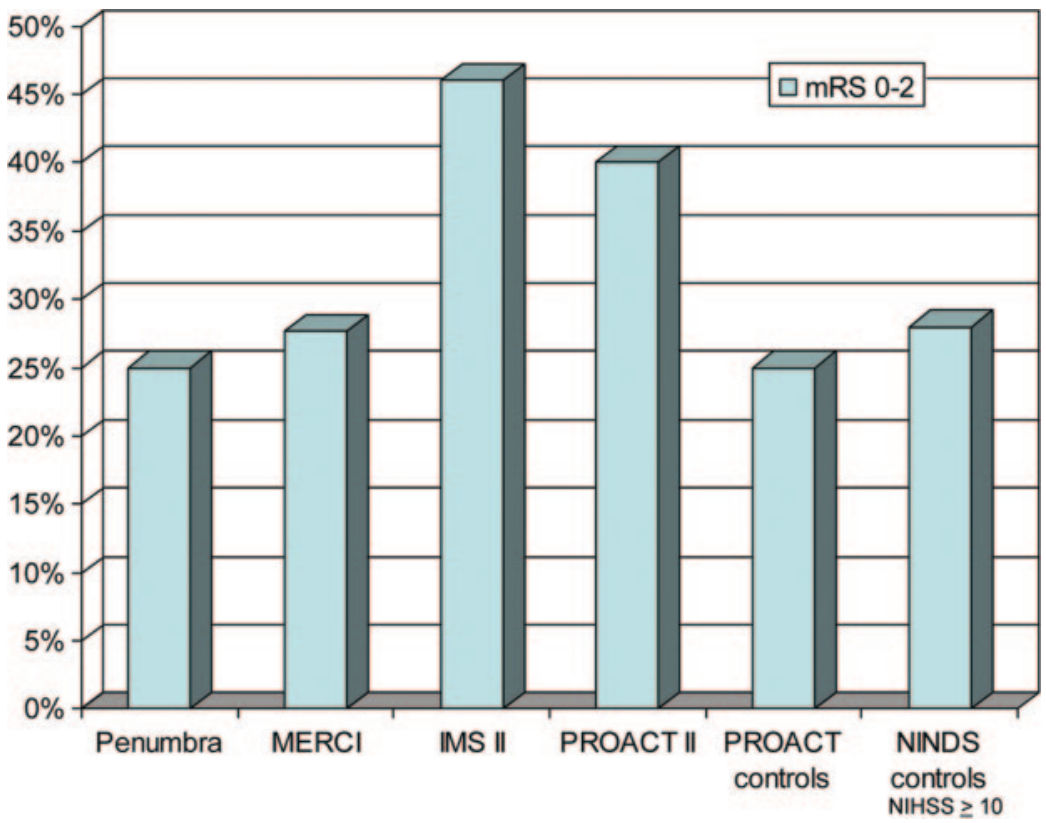

Percentage of patients with modified Rankin Scale (mRS) score of 0-2 at 90 days. IMS = Interventional Management of Stroke; $\mathrm{MERCI}=$ Mechanical Embolus Removal in Cerebral Ischemia; NINDS = National Institute of Neurological Disorders and Stroke; PROACT = Prolyse in Acute Cerebral Thromboembolism. higher recanalization rates $(>80 \%)$ than in the Mechanical Embolus Removal in Cerebral Ischemia (MERCI) trials. However, definitions of successful recanalization were different. Successful recanalization in the MERCI trials was defined as TIMI 2/3 in all treatable vessels, whereas recanalization of only the primary occlusion was reported in the Penumbra trial. Overall, accounting for potential differences in reporting recanalization and defining TIMI flow within recent stroke trials, the PS compares very favorably to other interventional stroke therapies with regard to successful vessel recanalization and serious adverse events, including sICH (figure 3).

However, functional outcome measures were not clearly improved with the use of the PS or the Merci device when compared with historical controls in the PROACT II ${ }^{19}$ and National Institute of Neurological Disease and Stroke trials ${ }^{1}$ (figure 4). In addition, the results for mechanical thrombectomy appear to suggest a worse outcome than those with thrombolytic therapies. However, this discrepancy may be explained by multiple variables, including differences in trial design, inclusion and exclusion criteria, stroke severity, distribution of occluded vessels, and time to initiating treatment. These differences, confounded by the small sample sizes of interventional stroke trials, currently limit any rigorous comparison of outcomes between the different interventional treatment modalities and medical management alone. As such, the American Stroke Association guidelines for the management of patients with AIS have not changed since 2007 with regard to mechanical thrombectomy, in that its usefulness as a treatment modality has not been established (Class IIb, level of evidence C). ${ }^{20}$

In our experience, the PS is an effective tool to safely revascularize large-vessel occlusions in patients within 8 hours of onset of AIS who are either refractory to or excluded from IV thrombolytic therapy. Further prospective, randomized controlled trials will be needed to address whether this ability translates into neurologic improvement and better functional outcomes for our patients.

\section{AUTHOR CONTRIBUTIONS}

Dr. Hussain: drafting/revising the manuscript, study concept or design, analysis or interpretation of data. Dr. Zaidat: drafting/revising the manuscript, study concept or design. Dr. Fitzsimmons: drafting/ revising the manuscript, study concept or design, analysis or interpretation of data, study supervision, acquisition of data, statistical analysis, and study supervision.

\section{DISCLOSURE}

Dr. Hussain reports no disclosures. Dr. Zaidat serves on the scientific advisory board for Talecris; served on the adjudication committee for Stryker; received speaker honoraria from Stryker; served on the editorial board of Frontiers in Neurology (Endovascular \& Interventional Neurology Section); serves as Editor of The Journal of Neurointerventional Surgery 
and serves as Associate Editor and is a member of the Editorial Board of Journal of Stroke \& Cerebrovascular Diseases; served as a consultant for Stryker Neurovascular-Commercial, Codman Neurovascular-Commercial, and Microvention Inc.-Commercial; and has received research support from a Society of Vascular \& Interventional Neurology (SVIN) grant for this educational activity. Dr. Fitzsimmons reports no disclosures. Go to Neurology.org for full disclosures.

Received July 21, 2011. Accepted in final form October 17, 2011.

\section{REFERENCES}

1. The National Institute of Neurological Disorders and Stroke rt-PA Stroke Study Group. Tissue plasminogen activator for acute ischemic stroke: The National Institute of Neurological Disorders and Stroke rt-PA Stroke Study Group. N Engl J Med 1995;333:1581-1587.

2. Hacke W, Kaste M, Fieschi C, et al. Randomised doubleblind placebo-controlled trial of thrombolytic therapy with intravenous alteplase in acute ischaemic stroke (ECASS II): Second European-Australasian Acute Stroke Study Investigators. Lancet 1998;352:1245-1251.

3. Albers GW, Bates VE, Clark WM, Bell R, Verro P, Hamilton SA. Intravenous tissue type plasminogen activator for treatment of acute stroke: the Standard Treatment with Alteplase to Reverse Stroke (STARS) study. JAMA 2000; 283:1145-1150

4. Bose A, Henkes H, Alfke K, et al. The Penumbra system: a mechanical device for the treatment of acute stroke due to thromboembolism. AJNR Am J Neuroradiol 2008;29: 1409-1413.

5. TIMI Study Group. Thrombolysis in Myocardial Infarction (TIMI) Trial: phase 1 findings. N Engl J Med 1985; 312:932-936

6. Khatri P, Wechsler LR, Broderick JP. Intracranial hemorrhage associated with revascularization therapies. Stroke 2007;38:431-440.

7. Penumbra Pivotal Stroke Trial Investigators. The penumbra pivotal stroke trial: safety and effectiveness of a new generation of mechanical devices for clot removal in intracranial large vessel occlusive disease. Stroke 2009; 40: 2761-2768.

8. Smith WS, Sung G, Starkman S, et al. Safety and efficacy of mechanical embolectomy in acute ischemic stroke: results of the MERCI trial. Stroke 2005;36:1432-1438.

9. Smith WS. Safety of mechanical thrombectomy and intravenous tissue plasminogen activator in acute ischemic stroke: results of the Multi Mechanical Embolus Removal in Cerebral Ischemia (MERCI) trial, part I. AJNR Am J Neuroradiol 2006;27:1177-1182.

10. Gobin YP, Starkman S, Duckwiler GR, et al. MERCI 1: a phase 1 study of mechanical embolus removal in cerebral ischemia. Stroke 2004;35:2848-2854.

11. Smith WS, Sung G, Saver J, Budzik R, et al. Mechanical thrombectomy for acute ischemic stroke: final results of the Multi MERCI trial. Stroke 2008;39:1205-1212.

12. The POST trial: initial post-market experience of the Penumbra system: revascularization of large vessel occlusion in acute ischemic stroke in the United States and Europe. J NeuroIntervent Surg 2010;2:341-344.

13. Jansen O, Schellinger P, Fiebach J, et al. Early revascularization in acute ischemic stroke saves tissue at risk defined by MRI. Lancet 1997;353:2036-2037.

14. Jansen O, von Kummer R, Forsting M, et al. Thrombolytic therapy in acute occlusion of the intracranial internal carotid artery bifurcation. AJNR Am J Neuroradiol 1995; 16:1977-1986.

15. Brandt $T$, von Kummer R, Muller-Kuppers $M$, et al. Thrombolytic therapy of acute basilar artery occlusion. Stroke 1996;27:875-881.

16. Wolpert SM, Bruckmann H, Greenlee R, et al. Neuroradiologic evaluation of patients with acute stroke treated with recombinant tissue plasminogen activator: the rt-PA Acute Stroke Study Group. AJNR Am J Neuroradiol 1993;14:3-13.

17. IMS Study Investigators. Combined intravenous and intra-arterial recanalization for acute ischemic stroke: the Interventional Management of Stroke Study. Stroke 2004; 35:904-911.

18. The IMS II Trial Investigators. The Interventional Management of Stroke (IMS) II Study. Stroke 2007;38:21272135.

19. Furlan A, Higashida R, Wechsler L, et al. Intra-arterial prourokinase for acute ischemic stroke: the PROACT II study: a randomized controlled trial. JAMA 1999;282: 2003-2011.

20. Adams HP Jr, del Zoppo G, Alberts MJ, et al. Guidelines for the early management of adults with ischemic stroke: a guideline from the American Heart Association/American Stroke Association Stroke Council, Clinical Cardiology Council, Cardiovascular Radiology and Intervention Council, and the Atherosclerotic Peripheral Vascular Disease and Quality of Care Outcomes in Research Interdisciplinary Working Groups. Stroke 2007;38:1655-1711. 


\section{Neurology}

\section{The Penumbra system for mechanical thrombectomy in endovascular acute ischemic stroke therapy}

Syed I. Hussain, Osama O. Zaidat and Brian-Fred M. Fitzsimmons

Neurology 2012;79;S135-S141

DOI 10.1212/WNL.0b013e31826958a8

This information is current as of September 24, 2012

\section{Updated Information \& \\ Services}

Supplementary Material

\section{References}

Subspecialty Collections

Permissions \& Licensing

Reprints including high resolution figures, can be found at: http://n.neurology.org/content/79/13_Supplement_1/S135.full

Supplementary material can be found at:

http://n.neurology.org/content/suppl/2012/09/23/79.13_Supplement_1. S135.DC1

http://n.neurology.org/content/suppl/2012/09/23/79.13_Supplement_1. S135.DC2

http://n.neurology.org/content/suppl/2012/09/23/79.13_Supplement_1. S135.DC3

This article cites 20 articles, 12 of which you can access for free at: http://n.neurology.org/content/79/13_Supplement_1/S135.full\#ref-list1

This article, along with others on similar topics, appears in the following collection(s):

All Cerebrovascular disease/Stroke

http://n.neurology.org/cgi/collection/all_cerebrovascular_disease_strok e

Information about reproducing this article in parts (figures,tables) or in its entirety can be found online at:

http://www.neurology.org/about/about_the_journal\#permissions

Information about ordering reprints can be found online:

http://n.neurology.org/subscribers/advertise

Neurology ${ }^{\circledR}$ is the official journal of the American Academy of Neurology. Published continuously since 1951, it is now a weekly with 48 issues per year. Copyright Copyright (? 2012 by AAN Enterprises, Inc.. All rights reserved. Print ISSN: 0028-3878. Online ISSN: 1526-632X.

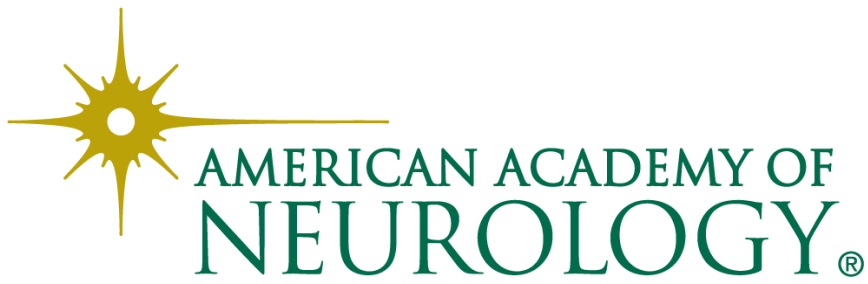

